(1)

\title{
Biologically active recombinant carp LH as a spawning-inducing agent for carp
}

\author{
Joseph Aizen, Lian Hollander-Cohen, Michal Shpilman and Berta Levavi-Sivan \\ The Robert H. Smith Faculty of Agriculture, Food and Environment, Department of Animal Sciences, \\ The Hebrew University of Jerusalem, Rehovot, Israel
}

Correspondence should be addressed to B Levavi-Sivan Email

berta.sivan@mail.huji.ac.il

\begin{abstract}
Currently, spawning is induced in carp species by carp pituitary extract (CPE) and a combination of synthetic agonist of $\mathrm{GnRH}$ combined with a dopamine antagonist. The main goal of this study was the production of recombinant gonadotropins (GtHs) on a large scale to serve as an alternative to currently used agents. We produced carp (c) recombinant ( $r$ ) Lh as a single chain in the methylotrophic yeast Pichia pastoris. Lha subunit was joined with Lhb subunit with a flexible linker of three glycine-serine repeats and six Histidines to form a mature protein, the $\beta$-subunit formed the $\mathrm{N}$-terminal part and the $\alpha$-subunit formed the C-terminal part. The ability of the rcLh to elicit biological response was tested by in vivo stimulation of estradiol (E2) and $17 \alpha, 20 \beta$ dihydroxy-4-pregnen-3-one (DHP) and by its in vivo potency to induce ovulation and spawning induction. rcLh tested in this work significantly enhanced both E2 and DHP secretion in a dose-dependent manner similar to the results obtained with CPE. E2 levels showed a moderate rise following the priming injection and a subsequent decrease during the rest of the trial. DHP levels were only increased after the resolving injection, approximately $5 \mathrm{~h}$ before spawning. At the highest dose of $\mathrm{rcLh}(350 \mu \mathrm{g} / \mathrm{kg} \mathrm{BW})$, the recombinant protein was more efficient than CPE in terms of both spawning success and fertilization rate. It is shown here that rcLh can elicit the secretion of DHP in vivo and actually trigger spawning. These novel findings introduce the potential of utilizing recombinant gonadotropins in aquaculture.
\end{abstract} Key Words

- carp

- $\mathrm{LH}$

- $\mathrm{FSH}$

- E2

$\rightarrow$ DHP
Journal of Endocrinology (2017) 232, 391-402

\section{Introduction}

Under the control of the hypothalamus, especially by the action of specific neuropeptides and gonadotropinreleasing hormone $(\mathrm{GnRH})$, the fish pituitary synthesizes and releases gonadotropins (GtHs). Follicle-stimulating hormone (Fsh) stimulates the recruitment and growth of early follicles and activates the synthesis and uptake of vitellogenin by E2 secretion, whereas luteinizing hormone (Lh) promotes final follicular maturation via the secretion of DHP (reviewed by Levavi-Sivan et al. 2010). The action of these hormones requires binding to specific receptors anchored in the plasma membrane of target cells of the gonads (granulosa and theca cells), and through the activation of certain pathways, the secretion of sex steroids is initiated (Levavi-Sivan et al. 2010). The common carp (c) Cyprinus carpio is probably the oldest cultured and most domesticated fish in the world. 
Carps (and related genera) represent $52 \%$ of the total aquaculture production from the world's inland waters with total harvest figures of over 28 million tons in 2014. In fish, as in mammals, within the same species, the $\alpha$-subunit is encoded by a single gene and is common to all glycoprotein hormones, whereas different genes encode $\beta$-subunits that confer specificity to the glycoprotein hormone heterodimers (Levavi-Sivan et al. 2010). One of the major goals of aquaculture practices is to artificially stimulate spawning via the manipulation of the hormonal axis (Yaron 1995). Manipulating various environmental parameters, such as temperature, photoperiod, salinity, tank volume and depth, substrate vegetation and so forth showed improvements in spawning for particular species (Mylonas \& Zohar 2001, Zohar \& Mylonas 2001). However, in some species, hormonal treatments are the only means of consistently controlling reproduction. A heterologous GtH from human origin (human chorionic GtH; hCG) proved to be a powerful spawning-inducing agent in finfish reproduction (Zohar \& Mylonas 2001). However, the response of cyprinid fish to hCG is notoriously poor (Kucharczyk et al. 1997, Yaron et al. 2009). Over the years, a variety of endocrine approaches have been considered to induce spawning in carps (reviewed by Yaron 1995, Yaron et al. 2002).

Gonadotropins, from various sources, have traditionally been used to stimulate folliculogenesis and ovulation in the treatment of infertility and in assisted reproductive technology (ART) in humans (Wallach et al. 1996). Similar to ART procedures, protocols currently used in aquaculture for spawning induction in carp is based on the use of native gonadotropins, such as calibrated carp pituitary extract (CCPE) (Levavi-Zermonsky \& Yaron 1986). Females are injected twice at an 11-h interval, and 8-11 h after the second injection, they usually spawn. Males are given a single dose of cCPE, containing a calibrated dose of Lh, via injection to induce spawning (Yaron et al. 1984). An alternative agent, based on hypothalamic hormones (DAGIN, Ovaprim or LinPe), involves a combination of synthetic, highly potent GnRH agonist with a dopamine antagonist (Peter et al. 1988b, Drori et al. 1994). However, the use of ground pituitaries is associated with various drawbacks; the most hazardous one is the potential for disease transmission from donor fish to recipient. Furthermore, the harvest procedure for carp pituitaries is labor-intensive. The usage of the hypothalamic approach also includes some disadvantages. As acute GnRHa action is dependent on the releasable pool of Lh in the pituitary of the recipient fish, DAGIN potency is limited to spawning induction during spring and early summer and is less potent at the beginning and end of the breeding season, with a low releasable pool (Kulikovsky et al. 1996). The interval between hormone administration and initial egg release (latency) is long (more than $14 \mathrm{~h}$ ) and highly variable (Drori et al. 1994). Due to these disadvantages, a reliable, low-cost product for artificial spawning induction with all year round availability in large quantities is needed. Recombinant Lh has all the advantages of the hypophyseal approach but does not carry the risk of distributing diseases and contamination. The main goal of this study was to establish a reliable spawning protocol that will use a single-chain recombinant carp Lh. We then wanted to determine if positively charged amino acid cluster, at the N-terminal portion of the carp $\alpha$-subunit, increases biological activity as it does in mammals, thereby allowing us to determine if structural constraints on hormone-receptor interactions are conserved between teleosts and mammals.

\section{Materials and methods}

\section{Fish}

Common carp, Cyprinus carpio, were collected from the ponds of a local farm (Kibbutz Gan-Shmuel, Israel) and were reared under standard aquaculture conditions (Levavi-Zermonsky \& Yaron 1986). All experimental procedures comply with the Animal Care and Use Guidelines of the Hebrew University and are approved by the local administrative panel on laboratory animal care.

\section{Recombinant gonadotropin production and purification}

The synthetic construct was based on the cDNA encoding the mature secreted form of $\operatorname{cLh} \beta$ (GenBank Accession No. M37380) and cLh $\alpha$ (GenBank Accession No. X56497) without their cognate signal peptide. A linker (Kasuto \& Levavi-Sivan 2005) was introduced, in addition to a Histag, to operate as a bridge between the $\beta$ - and $\alpha$-subunits.

\section{Selection and expression}

The procedure was generally performed according to Aizen et al. (2007a) and Kasuto \& Levavi-Sivan (2005). Recombinant proteins were purified using nickelnitrilotriacetic acid-agarose (Ni-NTA; Qiagen). As a negative control, $P$. pastoris was transformed with an expression vector that did not contain the CLH CDNA, and fractions were prepared in the same manner.

Published by Bioscientifica Ltd. 


\section{Prediction of proper folding of the recombinant protein}

Proper folding was determined by a unified platform for automated protein structure and function prediction. Proteins models were prepared by the iterative threading assembly refinement server I-TASSER server (Roy et al. 2010). Visualization and superposition of the models were performed using Accelrys Discovery Studio package (version 2.5). All models superposed by their backbone atoms based on the multiple sequence alignment.

\section{Transfection and luciferase reporter gene assay}

Transactivation of the cLh receptor, transient transfection, cell procedures and stimulation protocols were generally conducted according to Aizen et al. (2012b).

\section{Spawning induction in carp}

Currently, protocols used in Israeli aquaculture for spawning induction in carp are based on that described by Levavi-Zermonsky \& Yaron (1986). Prior to spawning induction experiments, oocytes from females that were ready for induced spawning were sampled and cleared in Serra's fluid (ethanol: 40\% formalin: acetic acid (6:3:1)). Then the position of the germinal vesicle (GV) was determined under a dissecting microscope according to Levavi-Zermonsky \& Yaron (1986) and Yaron \& LevaviZermonsky (1986). Oocyte maturation was categorized into the following stages: I, central GV; II, migrating GV; III, peripheral GV; IV, GV breakdown (GVBD); and $\mathrm{V}$, ovulated eggs in the ovarian lumen. Only fish possessing over $60 \%$ oocytes at stage II were selected for the spawning experiments. Briefly, female common carp were injected with calibrated carp pituitary extract (cCPE) containing $0.07 \mathrm{mg} \mathrm{cGtH} / \mathrm{kg} \mathrm{BW}$ as a priming dose, and $11 \mathrm{~h}$ later, with cCPE containing $0.23-0.35 \mathrm{mg}$ $\mathrm{cGtH} / \mathrm{kg}$ BW as a resolving dose. Eight to $11 \mathrm{~h}$ after the second injection, the females spawned. In the current work, female carp were injected following the same protocol but with graded doses $(5,50,100,200$ and $350 \mu \mathrm{g} / \mathrm{kg} \mathrm{BW}$ ) of rcLh to precisely determine the dose of pure rLH that would lead to successful spawning. The priming dose was always $1 / 10$ of the resolving dose. Each group consisted of at least six mature females, selected as ready for induced spawning (i.e. more than $60 \%$ of their oocytes contained eccentric (migrating) GV). Spawning success was determined by the number and volume of eggs spawned, percent of fertilization and embryo survival.

\section{ELISA for E2 and DHP}

E2 and DHP levels were determined by specific ELISAs according to established protocols (Hurvitz et al. 2005). The lowest limit of detection was $1.56 \mathrm{pg} / \mathrm{mL}$ for either E2 or DHP. The intra- and inter-assay coefficients of variation were less than $7 \%$ and $11 \%$, respectively.

\section{ELISA for carp Lh}

Specific and homologous ELISA for the determination of cLH was performed according to Aizen et al. (2007b) with certain modifications. The ELISA was carried out using primary antibodies against cLH $\beta$ according to Aizen et al. (2012a). Recombinant cLH $\beta \alpha$ was used to create the standard curves. The wells were coated with cLH $\beta$ (produced according to Kasuto \& Levavi-Sivan (2005); $0.2 \mathrm{ng} /$ well), the antibodies were diluted 1:7000. The intra-assay and inter-assay coefficients of variation were $7.6 \%$ and $11.3 \%$, respectively; sensitivity of the assay was $32 \mathrm{pg} / \mathrm{mL}$.

\section{Statistical analysis}

All data are presented as mean \pm s.E.M., and the significance of difference between group means were determined by one-way ANOVA followed by Newman-Keuls test with $P<0.05$ using the GraphPad Prism 6.05 software (GraphPad).

\section{Results}

\section{Optimizing linkers for recombinant carp Lh}

Recombinant cLh production was performed as described previously (Aizen et al. 2012a), and to enhance the efficiency of GtH production, fusion between the two subunits by a flexible linker was required. The Gly-Ser linker sequence is minimally hydrophobic or charged and can therefore promote the chimerization of the subunits to fold into their native conformational structures and interact with their receptors. We tested four different linkers based on the Gly-Ser string: 3x(Gly-Ser), 5x(Gly-Ser), $3 x\left(\mathrm{Gly}_{4} \mathrm{Ser}\right)$ and $2 \mathrm{x}\left(\mathrm{Gly}_{4} \mathrm{Ser}\right)$. The $\alpha$ - and $\beta$-subunits of cLH, with each of these linkers, were constructed and expressed in the yeast. The restriction enzyme BtgI was used to cut the His-tag linker. Two parts emerged (Fig. 1): one contained the $\beta$-subunit and the last His amino acid of the six Histag; the second contained the cut His-tag and the linker http://joe.endocrinology-journals.org DOI: 10.1530/JOE-16-0435 (c) 2017 Society for Endocrinology Printed in Great Britain
Published by Bioscientifica Ltd. 


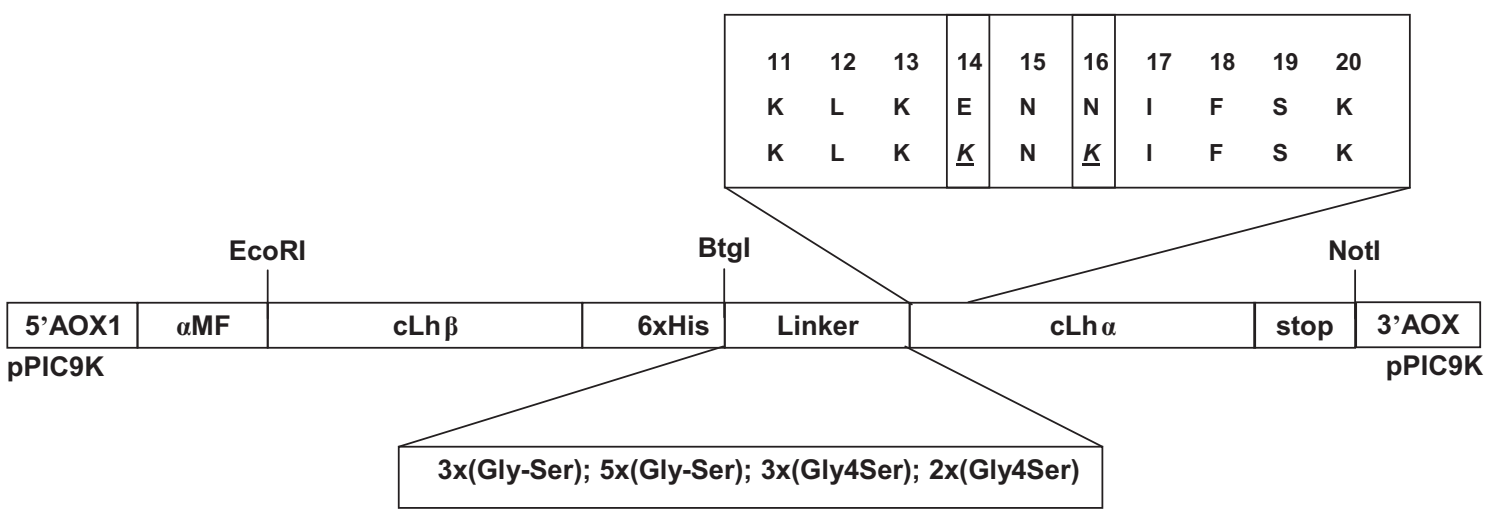

Figure 1

Insertion of different linkers: 3x(Gly-Ser); 5x(Gly-Ser); 3x(Gly4Ser); 2x(Gly4Ser) and mutation in the $\alpha$-subunit 11-20 region, Glu(E) and Asp(N), at positions 14 and 16 , respectively, to Lys $(K)$ residues .

attached to the $\alpha$-subunit. All tested linkers were added to the second part with specific primers (Table 1), ligation was performed and the new construct with the novel linker was subcloned into pPIC9K expression vector.

To better predict correct folding of the rcLh bearing the various linkers, the constructs were further analyzed by I-TASSER server. According to the I-TASSER server results, the proteins with the $3 x(\mathrm{Gly}-\mathrm{Ser}), 3 \mathrm{x}\left(\mathrm{Gly}_{4} \mathrm{Ser}\right)$ and $2 \mathrm{x}\left(\mathrm{Gly}_{4} \mathrm{Ser}\right)$ were properly folded and exhibited the same binding sites (Fig. 2A, C and D, respectively). The protein with the $5 \mathrm{x}$ (Gly-Ser; Fig. 2B) linker lacked an active binding site due to the distortion effect on the protein structure. The protein with the $2 \mathrm{x}\left(\mathrm{Gly}_{4} \mathrm{Ser}\right)$ linker distorted the protein as well, but the binding site was not affected. The four proteins were produced after their constructs were inserted into the Pichia vector (3x (Gly-Ser); $\left.5 \mathrm{x}(\mathrm{Gly}-\mathrm{Ser}) ; \quad 3 \mathrm{x}\left(\mathrm{Gly}_{4} \mathrm{Ser}\right) ; \quad 2 \mathrm{x}\left(\mathrm{Gly}_{4} \mathrm{Ser}\right)\right)$ and tested for activation by the GtH receptor assay (Fig. 3).

When 3x(Gly-Ser) linker was used, and the construct was significantly more potent at stimulating cAMP production, with $\mathrm{EC}_{50}=44.24 \pm 0.05$. However, when the linker was $3 x\left(\mathrm{Gly}_{4} \mathrm{Ser}\right)$, the activity was reduced $\left(\mathrm{EC}_{50}=20.81 \pm 0.30 ;\right.$ Fig. 3$)$. The other two linkers, $5 \mathrm{x}$ (Gly-Ser) and $2 \mathrm{x}\left(\mathrm{Gly}_{4} \mathrm{Ser}\right)$ were not effective at all (Fig. 3). These results were aligned with the predictions of the
I-TASSER server, and based on these results, we continued the in vivo experiments with the construct containing $3 x$ (Gly-Ser) as a linker.

\section{Formation of carp Lh analog}

After determining the most efficient linker (3xGly-Ser), the next step was to produce a cLh analog that would enhance the biological activity. The amino acid 11-20 in the $\alpha$-subunit of vertebrate LH contains a cluster of lysine residues forming a domain that is critical for receptor binding and signal transduction. This domain is shown to play an important role in the evolution of glycoprotein hormone activities (Szkudlinski et al. 1996). Two amino acids (glutamic acid (Glu; E) and asparagine (Asn; N), at positions 14 and 16, respectively, in this region) were replaced by lysine (Lys; $\mathrm{K}$ ) residues giving rise to a mutated cLH, E14K+N16K. The altered sequence was subcloned into pPIC9K and was expressed.

\section{In vivo experiments}

We tested the rcLh in in vivo trials. A large amount of protein was produced from 2L media, yielding $313.66 \pm 2.29 \mu \mathrm{g} / \mathrm{L}(n=8)$. The average time for protein

Table 1 Primers used for amplification and insertions of linkers.

\begin{tabular}{l} 
Primer \\
\hline 2x(Gly4Ser)-linker \\
3x(Gly4Ser)-linker \\
5xGS-linker \\
carpLHba-1F \\
carpLHba-689R \\
pic-seq-F \\
pic-seq-R
\end{tabular}

\section{Primer}

5xGS-linker

carpLHba-1F

pic-seq-F

\begin{tabular}{l}
\hline Sequence \\
CCACGGAGGTGGTGGATCTGGAGGTGGTGGATCTTACCCAAGAA \\
CCACGGAGGTGGTGGATCTGGAGGTGGTGGATCTGGAGGTGGTGGATCTTACCCAAGAA \\
CCACGGTTCTGGTTCTGGTTCTGGTTCTGGATCTTACCCAAGAA \\
GAATTCTCTTACTTGCCACCATGTG \\
GCGGCCGCTTAGGACTTGTGGTAGTAA \\
TACTATTGCCAGCATTGCTGC \\
GGCAAATGGCATTCTGACATCCTC \\
\hline
\end{tabular}

http://joe.endocrinology-journals.org DOI: 10.1530/JOE-16-0435
๑๐ 2017 Society for Endocrinology Printed in Great Britain
Published by Bioscientifica Ltd 
A

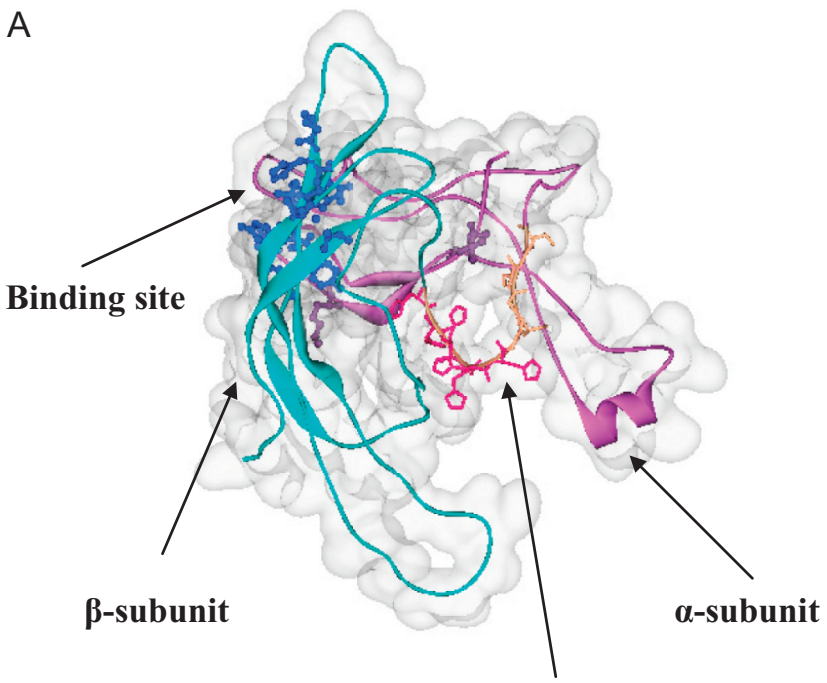

His tag + linker
B

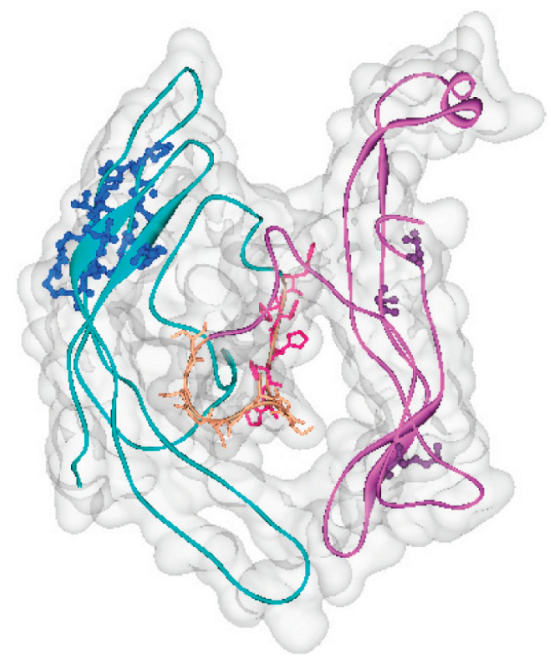

C

D

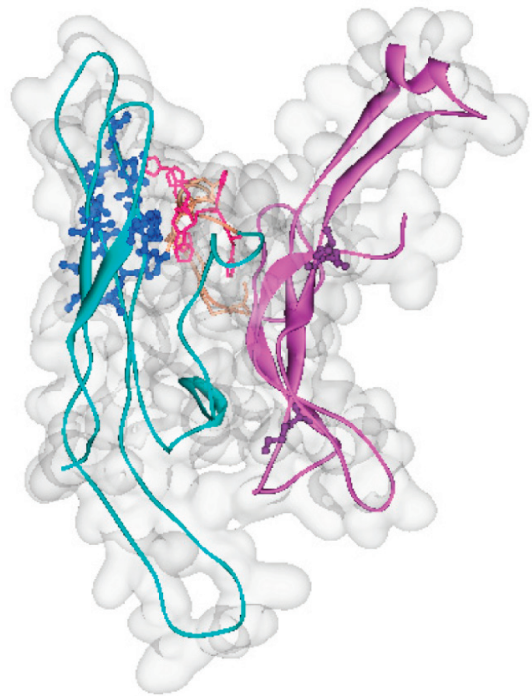

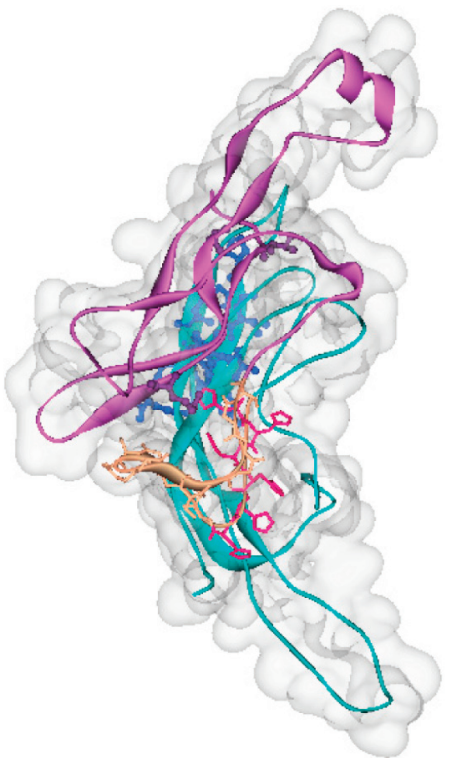

Figure 2

Models of rcLh $\beta \alpha$ with different linkers using the I-TASSER server. The resulting models for (A) 3x(Gly-Ser); (B) 5x(Gly-Ser); (C) 2x(Gly Ser); (D) 3x(Gly ${ }_{4} \mathrm{Ser}_{4}$; the common $\alpha$-subunit is marked in purple, the $\beta$-subunit in light blue, the His-tag in red and the linker in orange. Binding sites in the $\alpha$-subunit (residues 192, 199, 218) are marked in dark purple and in the $\beta$-subunit $(14,26,60-64,75-79)$ in dark blue.

production was 3 days of growth and 3 days of induction followed by 4 days of purification and validation. CPE served as a positive control, whereas saline as a negative one. Mature female carp were examined and found ready to spawn (i.e. more than $60 \%$ of their oocytes contained eccentric (migrating) GVs (Levavi-Zermonsky \& Yaron 1986, Yaron \& Levavi-Zermonsky 1986, Yaron et al. 2009)). $\mathrm{rcLh} \beta \alpha$ was tested at doses of: 5,50 and $100 \mu \mathrm{g} / \mathrm{kg}$ BW, all doses administered were followed by increased level of both E2 and DHP, the response being dependent on the dose (Fig. 4A). After injection by either CPE or Printed in Great Britain
() 2017 Society for Endocrinology
$100 \mu \mathrm{g} / \mathrm{kg} \mathrm{BW} \mathrm{rcLh} \beta \alpha$, E2 levels followed a similar pattern: a rise after the first injection and a subsequent decrease throughout the rest of the trial. However, E2 levels in fish injected with 5 or $50 \mu \mathrm{g} / \mathrm{kg}$ BW did not reach the levels as high as in those of fish treated with CPE (Fig. 4A). As shown in Figure 4B, $\operatorname{rcLh} \beta \alpha$ at 50 and $100 \mu \mathrm{g} / \mathrm{kg}$ BW was successful at elevating DHP levels to $4.17 \pm 1.43 \mathrm{ng} / \mathrm{mL}$ after the priming injection similar to the effect observed after CPE injection. No change was observed in DHP levels in the control fish or the lowest dose $(5 \mu \mathrm{g} / \mathrm{kg} \mathrm{BW})$ as the priming injection (Fig. 4B). After the resolving injection,

Published by Bioscientifica Ltd 


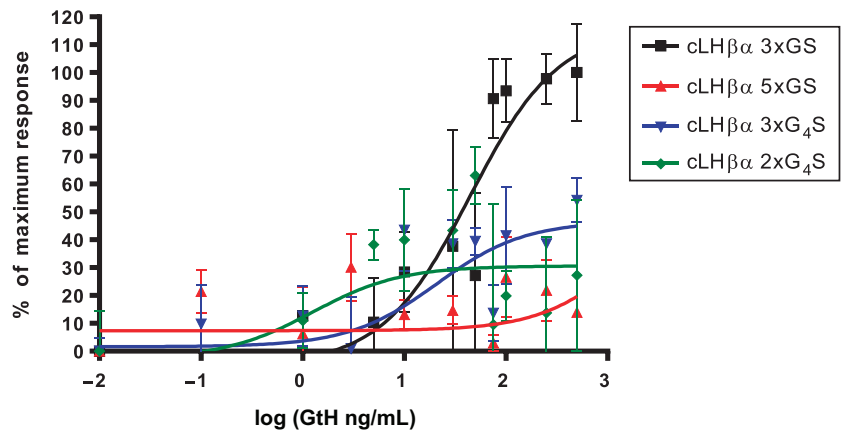

Figure 3

rcLHs induced CRE-derived transcriptional activity. COS-7 cells were transiently co-transfected with cLHR and with the reporter plasmid pCRE-LUC. Cells were stimulated for $6 \mathrm{~h}$ with $\mathrm{CLH} \beta \alpha$ with different linkers (3xGly-Ser, $5 x$ Gly-Ser, $3 x_{\text {Gly }}$ Ser and $2 x$ Gly $_{4}$ Ser) at different concentrations. Luciferase activity was determined, and results are presented as $\%$ of maximum response. Each assay was repeated at least three times. Data are presented as mean \pm S.E.M. of a representative experiment, performed in triplicate. The $\mathrm{EC}_{50}$ values are calculated from the nonlinear regression curve.

hormone levels in fish injected with CPE continued to rise, resulting in spawning, whereas $\operatorname{rchh} \beta \alpha$ at doses of 5 , 50 and $100 \mu \mathrm{g} / \mathrm{kg}$ maintained the same level of DHP, and no spawning was observed. All females injected with CPE spawned, while none of the $\operatorname{rch} \beta \alpha$-injected or control fish spawned (Table 2). CPE priming injection was followed by an increase in cLH levels up to $607.23 \pm 10.56 \mathrm{ng} / \mathrm{mL}$ (Fig. 4C). As expected, injection of the resolving dose was followed by a further increase in Lh, reaching a level of $954.47 \pm 26.50 \mathrm{ng} / \mathrm{mL}$. The $\operatorname{rcLh} \beta \alpha$ at the $100 \mu \mathrm{g} / \mathrm{kg}$ dose induced similar levels as the CPE treatment after the priming injection, but LH levels reached only $547.93 \pm 88.15 \mathrm{ng} / \mathrm{mL}$ following the resolving dose.

We next tested higher doses of $\operatorname{rcLh} \beta \alpha(200 \mu \mathrm{g} / \mathrm{kg})$ and $\operatorname{rcLH} \beta \alpha$ that was mutated in the $\alpha$-subunit ( $\operatorname{rcLh} \beta \alpha$-mut; $\mathrm{E} 14 \mathrm{~K}+\mathrm{N} 16 \mathrm{~K})$ at two doses $(100 \mu \mathrm{g} / \mathrm{kg}$ and $200 \mu \mathrm{g} / \mathrm{kg})$. In fish that were injected with $200 \mu \mathrm{g} / \mathrm{kg}$ BW, rcLh $\beta \alpha$-mut and $\operatorname{rcLH} \beta \alpha$, we found the same trend: elevated levels of $\mathrm{E} 2$ and DHP appeared after the priming injection and again after the resolving injection, DHP reached $3.23 \pm 1.01 \mathrm{ng} / \mathrm{mL}$; the CPE group reached a level of $21.62 \pm 5.84 \mathrm{ng} / \mathrm{mL}$ (Fig. 5A and $\mathrm{B}$ ). Injection of the $\mathrm{CPE}$ priming dose was followed by an increase in cLh levels up to $256.46 \pm 13.39 \mathrm{ng} / \mathrm{mL}$ (Fig. 5C). Injection of the resolving dose increased Lh levels, reaching $697.88 \pm 4.45 \mathrm{ng} / \mathrm{mL}$. Consistent with the DHP results, the Lh levels showed a similar pattern. In the $200 \mu \mathrm{g} / \mathrm{kg}$ BW $\operatorname{rcLh} \beta \alpha$-mut and $200 \mu \mathrm{g} / \mathrm{kg}$ BW rcLH $\beta \alpha$ groups, three out of six females actually spawned (25\% of fertilization), while fish injected with $100 \mu \mathrm{g} / \mathrm{kg}$, no spawning was observed. In the CPE-injected group, all females spawned $(65 \%$ of
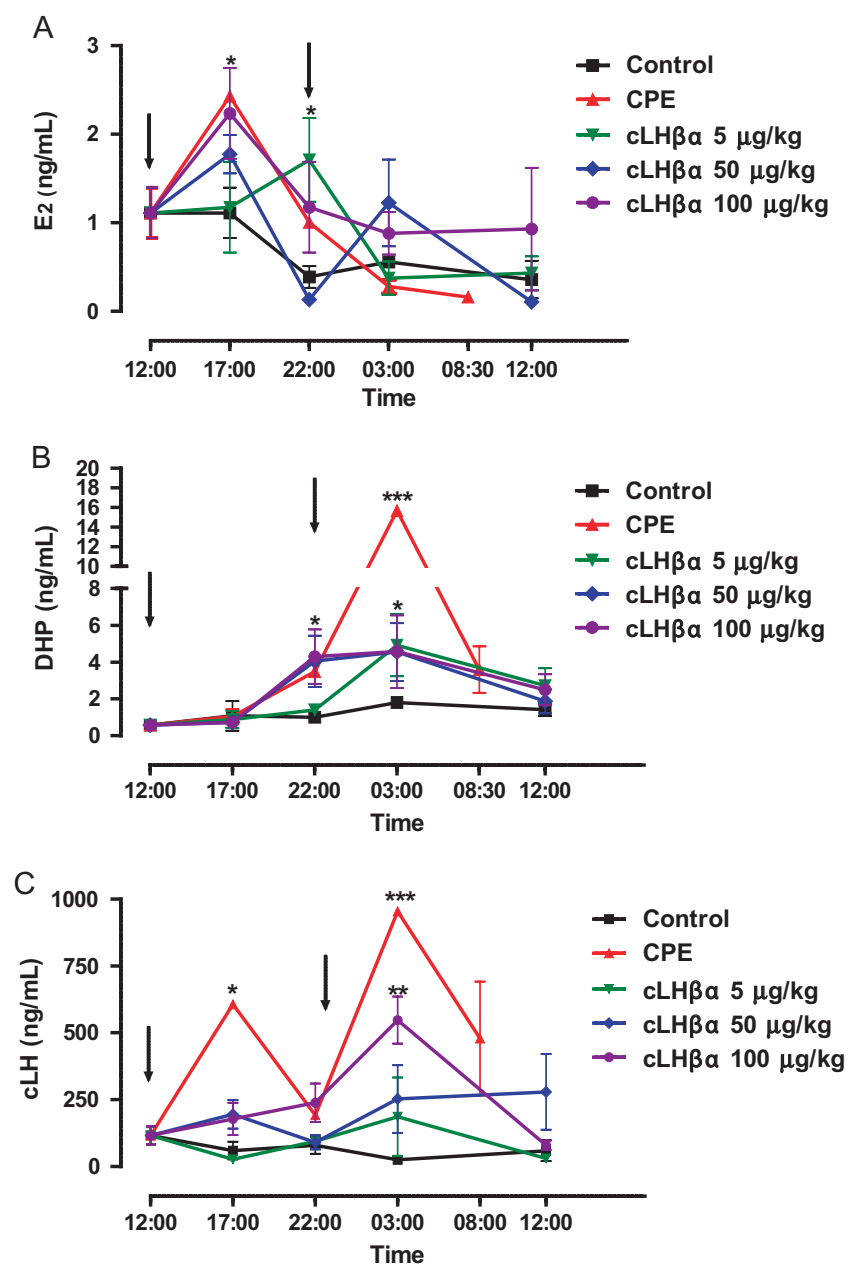

Figure 4

Concentration of E2 (A), DHP (B) and CLH (C) in the plasma of female carp, after injection of carp pituitary extract (CPE) or different doses of $\operatorname{CLH} \beta \alpha(5,50$ and $100 \mu \mathrm{g} / \mathrm{kg})$. Black arrows indicate priming (at 12:00 h) and resolving (at 22:00 h) injections, respectively. Data are presented as mean \pm S.E.M.; Statistically significant differences from controls are marked by asterisks $\left({ }^{*} P<0.05, * * P<0.01\right.$ and $\left.* * * P<0.001\right)$.

fertilization) (Table 2). A higher dose of $\operatorname{rcLh} \beta \alpha(350 \mu \mathrm{g} / \mathrm{kg})$ was tested, and the priming injection caused elevation of $\mathrm{E} 2$, whereas the resolving injection triggered an increase in DHP (Fig. 6A and B). E2 levels of the $\operatorname{rcLh} \beta \alpha$-injected females did not reach as high levels as the CPE-treated group. DHP levels, both in rcLh $\beta \alpha$ and CPE-injected fish, reached $21.64 \pm 13.86 \mathrm{ng} / \mathrm{mL}$ and $19.21 \pm 5.69 \mathrm{ng} / \mathrm{mL}$, respectively after the resolving injection. As expected, injection of the CPE and $\operatorname{rcLh} \beta \alpha$ was followed by an increase in cLh circulatory levels. In fish injected with $\operatorname{rcLh} \beta \alpha(350 \mu \mathrm{g} / \mathrm{kg} B W)$, eight out of ten females spawned ( $22 \%$ of fertilization), fish injected with saline did not spawn at all, whereas in the CPE-injected group, all females spawned (31.5\% of fertilization) (Table 2 ).

Published by Bioscientifica Ltd 
Table 2 Female body weight, oocyte diameter and latency period are expressed as mean \pm S.E.M.

\begin{tabular}{|c|c|c|c|c|c|c|c|}
\hline Treatment & $\begin{array}{l}\text { No. of injected } \\
\text { females }\end{array}$ & $\begin{array}{l}\text { No. of spawned } \\
\text { females }\end{array}$ & $\begin{array}{l}\text { Female body } \\
\text { weight }(g)^{1}\end{array}$ & $\begin{array}{c}\text { Oocyte } \\
\text { diameter }(\mu \mathrm{m})^{2}\end{array}$ & $\begin{array}{l}\text { Latency period } \\
(\mathrm{h})^{3}\end{array}$ & $\begin{array}{c}\text { Spawning } \\
\text { success }(\%)^{4}\end{array}$ & $\begin{array}{l}\text { Fertilization } \\
\text { rate }(\%)^{5}\end{array}$ \\
\hline \multicolumn{8}{|l|}{ Exp.1 } \\
\hline Control (Saline) & 6 & 0 & & & - & - & - \\
\hline $\operatorname{rcLH} \beta \alpha(5 \mu \mathrm{g} / \mathrm{kg})$ & 6 & 0 & & & - & - & - \\
\hline $\operatorname{rcLH} \beta \alpha(50 \mu \mathrm{g} / \mathrm{kg})$ & 6 & 0 & $153.90 \pm 6.86$ & $1290 \pm 20.20$ & - & - & - \\
\hline $\operatorname{rcLH} \beta \alpha(100 \mu \mathrm{g} / \mathrm{kg})$ & 6 & 0 & & & - & - & - \\
\hline CPE & 6 & 6 & & & 10.5 & 100 & 93 \\
\hline \multicolumn{8}{|l|}{ Exp.2 } \\
\hline Control (Saline) & 6 & 0 & & & - & - & - \\
\hline $\operatorname{rcLH} \beta \alpha(200 \mu \mathrm{g} / \mathrm{kg})$ & 6 & 3 & $186.9 \pm 10.78$ & $1310 \pm 34.76$ & 12 & 50 & 25 \\
\hline $\mathrm{rcLH} \beta \alpha(100 \mu \mathrm{g} / \mathrm{kg}) \mathrm{mut}$ & 6 & 0 & & & - & - & - \\
\hline $\mathrm{rcLH} \beta \alpha(200 \mu \mathrm{g} / \mathrm{kg}) \mathrm{mut}$ & 6 & 3 & & & 12 & 50 & 23 \\
\hline CPE & 6 & 6 & & & 10.5 & 100 & 65 \\
\hline \multicolumn{8}{|l|}{ Exp.3 } \\
\hline Control (Saline) & 10 & 0 & & & - & - & - \\
\hline $\mathrm{rcLH} \beta \alpha 350 \mu \mathrm{g} / \mathrm{kg}$ & 10 & 8 & $569.71 \pm 62.76$ & $1370 \pm 10.34$ & 10.5 & 80 & 31.5 \\
\hline CPE & 10 & 10 & & & 10.5 & 100 & 22 \\
\hline
\end{tabular}

${ }^{1}$ Mean \pm S.E.M. of female BW (g) in experiment group. ${ }^{2}$ Mean \pm S.E.M. of oocyte diameter ( $\mu$ m) in experiment group. ${ }^{3}$ Latency periods: time (h) between resolving injection and spawning. ${ }^{4}$ Spawning success (\%): the number of females that ovulated after injection, divided by the total number of injected females. ${ }^{5}$ Fertilization (\%): the number of eggs that were fertilized divided by the total number of eggs sampled.
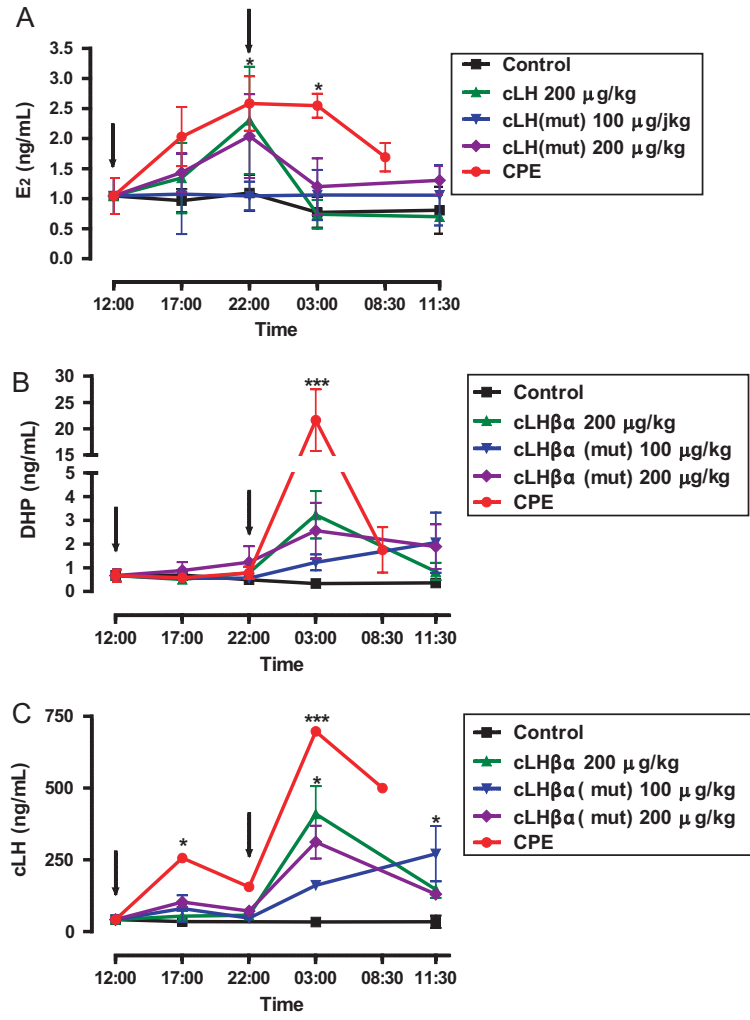

Figure 5

Concentration of E2 (A), DHP (B) and CLH (C) in the plasma of female carp, after injection of carp pituitary extract (CPE), $\mathrm{CLH} \beta \alpha(200 \mu \mathrm{g} / \mathrm{kg})$ and $\mathrm{CLH} \beta \alpha$ (mut) at different doses (100 and $200 \mu \mathrm{g} / \mathrm{kg}$ ). Black arrows indicate priming (at 12:00 h) and resolving (at 22:00 h) injections, respectively. Data are presented as mean \pm S.E.M. Statisticallysignificant differences from controls are marked by asterisks $(* P<0.05, * * P<0.01$ and $* * * P<0.001)$.

\section{Discussion}

The present study demonstrates the use of recombinant cLh for spawning induction in carp species. Biological availability was proven through in vivo stimulation of E2 and DHP secretion and by its potential to induce ovulation and spawning. For the last three decades, two main spawning induction agents have been used for spawning induction in carp species: CPE and an agent that is based on hypothalamic hormones like DAGIN, LinPe or Ovaprim (Peter et al. 1988a, Drori et al. 1994, Brzuska 2005). The CPE is mainly used to support spawning at the beginning and at the end of the seasonal reproduction period, whereas the rest are commonly used in mid-season. The use of native pituitaries, however, has some drawbacks, the most important is the transmission of hazardous material from donor fish to recipient broodstocks. Moreover, collection of pituitaries has to be carried out by trained stuff and is labor-intensive, which makes it expensive. In recent years, there has been a shortage of carp glands in the international market due to herpes virus disease among carp and koi (Davidovich et al. 2007), which lead to a legal restriction for importing fresh and processed pituitaries in several countries. The DAGIN/LinPe/Ovaprim method is widely used, but has some shortcoming. As acute GnRHa action is dependent on the endogenous releasable pool of $\mathrm{Lh}$ in the pituitary of the recipient fish, their potency is limited to spawning induction during spring and early summer and is less potent at the beginning and end of

Published by Bioscientifica Ltd. 
A

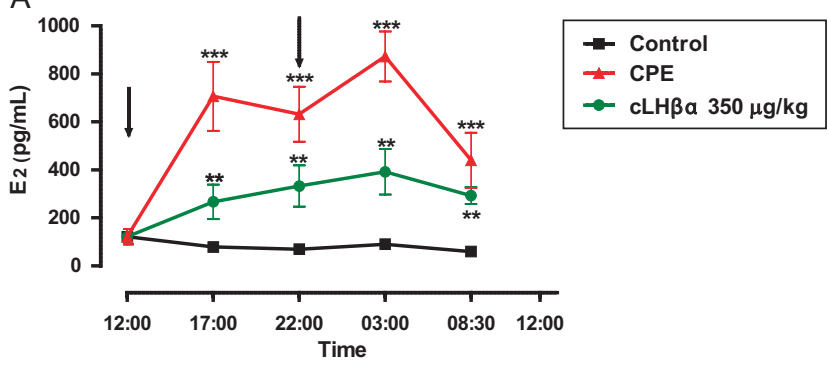

B

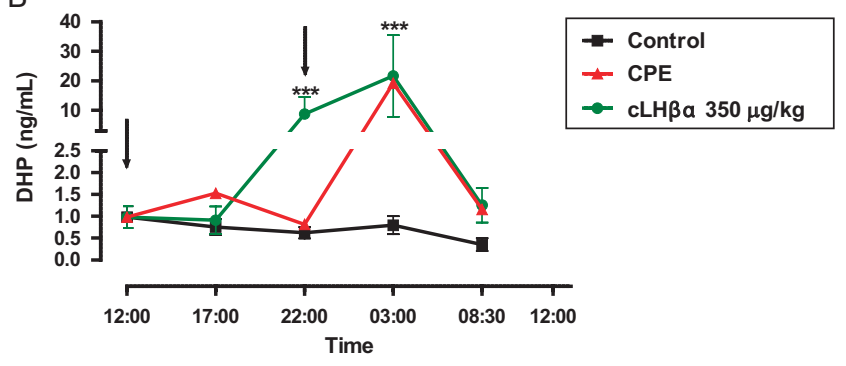

C

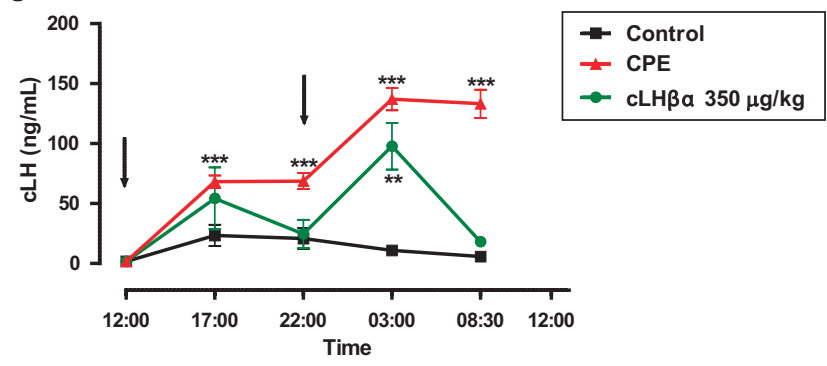

Figure 6

Concentration of E2 (A), DHP (B) and CLH (C) in the plasma of female carp, after injection of carp pituitary extract (CPE) or $\mathrm{CLH} \beta \alpha(350 \mu \mathrm{g} / \mathrm{kg})$. Black arrows indicate priming (at 12:00 h) and resolving (at 22:00 h) injections, respectively. Data are presented as mean \pm s.E.M. Statistically significant differences from controls are marked by asfterisks $\left({ }^{*} P<0.05\right.$, $* * P<0.01$ and $* * * P<0.001)$.

the breeding season when this pool of the hormone is generally low (Kulikovsky et al. 1996, Yaron et al. 2009). In addition, when using DAGIN, the latency is relatively long and variable (Drori et al. 1994). Due to these disadvantages, a need for a new approach emerged and the use of recombinant GtHs was suggested. It was anticipated that the next generation of spawning induction agents would involve the use of molecular tools to produce recombinant GtHs at an affordable cost (Yaron et al. 2009). Earlier work conducted in our laboratory showed that the $P$. pastoris expression system can be used to achieve singlechain tethered LH and FSH of tilapia (Kasuto \& LevaviSivan 2005, Aizen et al. 2007a). We used a P. pastoris expression system to produce rcLH in large scale. Most of the GtHs expressed to date in P. pastoris in tethered form have been hCGs (Sen Gupta \& Dighe 1999, 2000).
In hCG, last 30 amino acids of the $\beta$-subunit contain a C-terminal peptide (CTP) that plays a pivotal role as a linker (Sugahara et al. 1995). Only when the CTP is placed on either the C-terminal end of the FSH or $\mathrm{LH}$ $\beta$-subunits or in the N-terminal region of the $\alpha$-subunits, assembly, secretion and signal transduction of the dimers are comparable to the wild-type hormones (Fares et al. 1992, Furuhashi et al. 1995, Sugahara et al. 1995). As cLh lacks any CTP-like structure at its C terminus, the fusion between the two subunits needed to be bridged by a flexible linker. A bridge consisting of Gly-Ser was chosen due to the fact that the linker sequence had to be minimally hydrophobic or charged, to maximize the opportunity of chimerization of the subunits to fold into their native conformational structures. This is crucial for their receptor-binding ability. Previously (Kasuto \& Levavi-Sivan 2005, Aizen et al. 2007a), we used a linker that consisted of three pairs of Gly-Ser that provided a certain distance between the $\alpha$ - and $\beta$-subunits. In recent years, progress in the production of recombinant GtHs has made the generation of single-chain analogs of originally dimeric proteins more feasible (Adams \& Boime 2008). The single-chain technology involves transfection of cells with DNA encoding both subunits combined in a single gene construct. Over the last decade, the use of computational (in-silico) methods has been developed and applied as a tool for pharmacological hypothesis, development of active component and studying their biological activities. We used an in-silico method that was further verified by in vivo experiments. Using modeling approach, we analyzed the sequences and the predicted structures of the proteins we intended to produce with regards to their native conformational structures and folding. Using the I-TASSER platform (Roy et al. 2010), four linkers were tested based on combinations of Gly-Ser repeats: 1. 3x(Gly-Ser), 2. 5x(Gly-Ser), 3. 3x(Gly4Ser), 4. $2 \mathrm{x}$ (Gly4Ser). The model construct bearing the $5 \mathrm{x}$ (Gly-Ser) linker showed no deformity but lacked an active binding site as well, probably due to the length of the linker that extended the distance between the subunits, which was too long for forming a binding pocket. All other constructs (1, 3 and 4) showed structural similarity and presented the same predicted binding pocket. Using these data, we were able to produce recombinant GtHs bearing linkers that showed proper folding; furthermore, the in-silico method was found to be reliable in predicting the constructs' potency for GtHR activation. The rcLh $\beta \alpha$ was examined for its ability to stimulate cAMP production in COS-7 cells expressing cLhR. This enabled us to compare the potency of different rcLhs with the activity of native

Published by Bioscientifica Ltd 
cLh purified from carp pituitaries. We found that the only rcLh carrying the $3 x$ (Gly-Ser) linker could activate cLHR opposite to the $5 \mathrm{x}$ (Gly-Ser) construct, which showed no binding site in the modeling analysis, was also found to lack any activation of the receptor, which implies that the in-silico method is useful in predicting which linkers have the potential to produce a successful single-chain molecule. The bioactivity of the single-chain analogs demonstrated that the folding of the $\alpha$ and $\beta$ components into the configuration required to associate with the GtHR is not impaired by the single-chain organization of the $\alpha$ and $\beta$ domains. The correct folding is likely facilitated by the intervening linker sequence. Importantly, the high proportion of Ser and Gly residues in the linker sequence makes this segment highly flexible and allows the $\alpha$ and $\beta$ domains of the single chain to fold into the active configuration. An additional benefit of incorporating the linker sequence into the single chain is that, much like the dimeric CTP-modified GtHs, the CTP linker or CTP portion of the single chain reduces the rate of clearance (Fares et al. 1992). In this regard, recombinant human FSH produced in the $\mathrm{CHO}$ system bearing a Gly-Serbased linker with the addition of N-linked glycosylation sites showed that the FSH analogs had higher biological capability. The addition of multiple carbohydrate side chains does not appear to interfere with protein folding and in fact, amplified glycosylation further enhances ovarian follicle growth in rats (Weenen et al. 2004). Furthermore, $\mathrm{N}$-linked analogs are easier to design because signal sequences are known for $\mathrm{N}$-linked glycosylation.

In the current work, after optimizing the protein with a suitable linker, the ability of rcLh to elicit a biological response was examined by in vivo stimulation of $\mathrm{E} 2$ and DHP secretion and by its potency to induce ovulation and spawning in mature carp females. The use of rcLh administered in two injections, as described in LevaviZermonsky \& Yaron (1986), resulted in elevated E2, DHP and cLh levels, culminating actual spawning at the high-dose treatment $(350 \mu \mathrm{g} / \mathrm{kg})$. All doses tested in this work significantly enhanced both E2 and DHP secretion in a dose-dependent manner, similar to injection of the native GtHs present in the CPE. E2 levels after injection with either CPE or graded doses of rcLH followed a similar pattern: a rise after the priming injection and a subsequent decrease throughout the remaining duration of the trial. DHP levels were elevated after the resolving injection, similar to the effect observed with CPE. These results are in line with previous findings in carp (Levavi-Zermonsky \& Yaron 1986, Kime \& Bieniarz 1987) as well as in other fish species (Levavi-Sivan et al. 2010). Proceeding resolving injection, DHP levels in the fish injected with CPE continued to rise, with a peak at $0300 \mathrm{~h}, 5 \mathrm{~h}$ before spawning. Only the highdose treatment of $350 \mu \mathrm{g} / \mathrm{kg}$ rcLh mimicked the CPE treatment with regard to DHP levels. The $200 \mu \mathrm{g} / \mathrm{kg}$ rcLh elicited DHP increase but with lower levels, and hence, a lower rate of spawning. It is assumed that the moderate increase in cLh after the priming injection stimulated the formation of the maturation-inducing hormone (MIS) DHP receptors on the plasma membrane of the oocytes rendering them sensitive to the MIS surge. Indeed, in sea trout, $6 \mathrm{~h}$ after exposure to $\mathrm{GtH}$, a two- to four-fold increase in oocyte and ovarian MIS receptors and the development of oocyte maturational competence (OMC: the ability to complete oocyte maturation in vitro in response to exogenous MIS (Thomas et al. 2001)) were observed. The decrease in E2 levels that was concomitant with the peak in DHP demonstrates a shift in the steroidogenic pathway from the formation of estrogens towards the formation of progestogens; this may involve a decrease in 17-20 lyase activity and a rise in $20 \beta$ hydroxysteroid dehydrogenase activity. In a number of teleost species, two genes encoding $17 \alpha$ hydroxylase (P450c17) have been detected. One is P450c17-I, which is similar to that in tetrapods and also displays the lyase activity that produces C19 steroids (androstenedione or dehydroepiandrosterone) which may serve as a precursor for estrogens. This type of P450c17 is expressed in the ovarian granulosa cells of vitellogenic follicles. P450c17-II encodes a $17 \alpha$ hydroxylase that is devoid of lyase activity and fully expressed in oocytes only during final oocyte maturation (Zhou et al. 2007, Nagahama \& Yamashita 2008). Irrespective of the mechanism leading to the steroidogenic shift, E2 and its 7TMD receptors $(\mathrm{GPR} 30=\mathrm{GPER})$ in the oocytes maintain meiotic arrest. Therefore, the decrease in E2 is essential for the resumption of meiosis during oocyte maturation (Pang \& Thomas 2009, Pang \& Thomas 2010). Recent work by Majumder et al. (2015) demonstrated the presence of such a mechanism in the common carp. The rcLh managed to elicit spawning as the CPE treatment. In the $200 \mu \mathrm{g} / \mathrm{kg}$ treatment, only $50 \%$ of the females spawned and a low percentage of fertility was achieved (around 25\%). Moreover, the latency period in females treated with rcLh was about 1.5 to $3 \mathrm{~h}$ longer than that in CPE-treated fish; this could be related to the fact that the DHP peak occurred later, and therefore, the spawning was delayed.
Published by Bioscientifica Ltd 
The 11-20 region in the $\alpha$-subunit is a cluster of basic residues present in all vertebrates except hominoids (apes and humans) and has been recognized as an important motif in the evolution of GTH bioactivity in primates (Szkudlinski 2004). Carp, catfish and goldfish possess lysine in positions 11,13 and 20, and bovines have lysine residues in positions $11,13,16$ and 20 , whereas humans have no lysine residues between positions 11-20 of their $\alpha$-subunit (Szkudlinski 2004). As the insertion of basic amino acids at positions 11-20 increase the binding and activation of the LH receptor in humans (Szkudlinski et al. 1996), we assumed that this is an ancient and conserved feature of glycoprotein hormones and their receptors, having evolved before the divergence of the LH and TSH-Rs. Surprisingly, the mutated cLh (E14K+N16K) did not exhibit any difference in hormone levels compared to the native rcLh and resulted in the same spawning ratio, fertility and latency period. Thus, the Lys substitution in the carp $\alpha$-subunit had no effect on the binding to its receptor or activation of rcLh, an effect that was prominent when applied to hCG (Szkudlinski et al. 1996). This can be explained by the large amount of basic residues which already exist in the carp 11-20 region in the $\alpha$-subunit (3 basic residues (Lys) at positions 11, 13 and 20). Recently, Miller and coworkers (Miller et al. 2012) found that the four positively charged lysines that substituted for neutral or negatively charged amino acids within positions 11-20 of the glycoprotein hormone $\alpha$-subunit, significantly increased the biological activity of hTSH in goldfish and in mammals. It should be noted that a recombinant human FSH analog based on mutated residues in the same region $(\mathrm{Q} 13 \mathrm{R}+\mathrm{E} 14 \mathrm{R}+\mathrm{P} 16 \mathrm{R}+\mathrm{Q} 20 \mathrm{R})$ increased $\mathrm{T}_{4}$ response in vivo in goldfish, whereas recombinant $\mathrm{hFSH}$ exhibited no thyrotrophic activity (Miller et al. 2012). Nevertheless they noted that the protein structure of GTH $\beta$-subunit in goldfish could also have contributed to the heterothyrotropic activity of the gonadotropin dimers. The promiscuity of the GTH and TSH receptors in fish in general and carp in particular need further investigation.

To date, only a few studies have shown in vivo use of recombinant GtHs in fish. In eel, the biological activity of recombinant $\mathrm{GtHs}$ was demonstrated in various in vitro assays. However, these recombinant GtHs exhibited little activity in the gonads when administered in vivo (Kazeto et al. 2008). Interestingly, recombinant FSH of Japanese eel was able to induce testicular growth and spermatogenesis in immature eels (Kamei et al. 2006, Ohta et al. 2007). In the orange-spotted grouper (g), treatment with $\mathrm{rgLh}$ resulted in marked increases in the mRNA levels of $\operatorname{Lh} \beta$ in the pituitary, hypothalamus and gonad of immature groupers. The mRNA levels of cyp19a1a and cyp19a1b also rose dramatically after injecting rgLh intraperitoneally (Cui et al. 2007). In Manchurian trout, single injection with trFsh, but not trLh, significantly increased mean GSI and follicle diameters compared with those of control fish, 3 days after injection (Ko et al. 2007). In goldfish, the production of single-chain Fsh and Lh was tested in vivo using male goldfish, female bitterling Rhodeus (Ocellatus ocellatus) and male Japanese eel. Injection of silkworm hemolymph containing single-chain FSH or LH induced milt production in male goldfish. Single-chain LH induced ovulation in bitterlings but single-chain $\mathrm{FSH}$ showed lower potency (Hayakawa et al. 2008). Recently, an injection of recombinant single-chain Fsh in sea bass increased the plasma levels of Fsh, which led to an increased 11-KT levels as well (Mazón et al. 2014).

Manipulation of reproduction processes by the administration of recombinant GtHs are frequently used in ART (Andersen \& Krummen 2002), but it is still not commonly used in livestock, and its application in aquaculture is essentially non-existent (Levavi-Sivan et al. 2008, Levavi-Sivan et al. 2010). The production of active GtHs in fish species can open a new age in aquaculture, as specific homologous treatments can be designed for the different reproductive disorders found in the domestication of new species.

To conclude, to the best of our knowledge, this is the first time that the production of a recombinant glycoprotein in fish, i.e. cLH, has been shown to elicit the production and secretion of DHP in in vivo trials and elicit actual spawning. These novel findings raise the possibility of using the recombinant hormone as a substitute for the currently used CPE and DAGIN/LinPe in carp spawning and in other fish species.

\section{Declaration of interest}

The authors declare that there is no conflict of interest that could be perceived as prejudicing the impartiality of the research reported.

\section{Funding}

This research was supported by Chief Scientist, Ministry of Economy and Industry, Israel Nufar grant (38847).

\section{Acknowledgments}

The authors would like to thank Kibbutz Gan-Shmuel Fish Farm for their enthusiastic assistance with fish care.

Published by Bioscientifica Ltd. 


\section{References}

Adams TE \& Boime I 2008 The expanding role of recombinant gonadotropins in assisted reproduction. Reproduction in Domestic Animals 43 186-192. (doi:10.1111/j.1439-0531.2008.01160.x)

Aizen J, Kasuto H, Golan M, Zakay H \& Levavi-Sivan B 2007a Expression and characterization of biologically active recombinant tilapia FSH: immunohistochemistry, stimulation by GnRH and effect on steroid secretion. Biology of Reproduction 76 692-700. (doi:10.1095/ biolreprod.106.055822)

Aizen J, Kasuto H \& Levavi-Sivan B 2007b Development of specific enzyme-linked immunosorbent assay for determining LH and FSH levels in tilapia, using recombinant gonadotropins. General and Comparative Endocrinology 153 323-332. (doi:10.1016/j. ygcen.2007.04.004)

Aizen J, Kobayashi M, Selicharova I, Sohn YC, Yoshizaki G \& LevaviSivan B 2012a Steroidogenic response of carp ovaries to piscine FSH and LH depends on the reproductive phase. General and Comparative Endocrinology 178 28-36. (doi:10.1016/j.ygcen.2012.04.002)

Aizen J, Kowalsman N, Kobayashi M, Hollander L, Sohn YC, Yoshizaki G, Niv MY \& Levavi-Sivan B $2012 b$ Experimental and computational study of inter- and intra- species specificity of gonadotropins for various gonadotropin receptors. Molecular and Cellular Endocrinology 364 89-100. (doi:10.1016/j.mce.2012.08.013)

Andersen DC \& Krummen L 2002 Recombinant protein expression for therapeutic applications. Current Opinion in Biotechnology 13 117-123. (doi:10.1016/S0958-1669(02)00300-2)

Brzuska E 2005 Artificial spawning of carp (Cyprinus carpio L.): differences between females of Polish strain 6 and Hungarian strain W treated with carp pituitary homogenate, Ovopel or Dagin. Aquaculture Research 36 1015-1025. (doi:10.1111/j.13652109.2005.01311.x)

Cui M, Li W, Liu W, Yang K, Pang Y \& Haoran L 2007 Production of recombinant orange-spotted grouper (Epinephelus coioides) luteinizing hormone in insect cells by the baculovirus expression system and its biological effect. Biology of Reproduction 76 74-84. (doi:10.1095/ biolreprod.105.050484)

Davidovich M, Dishon A, Ilouze M \& Kotler M 2007 Susceptibility of cyprinid cultured cells to cyprinid herpesvirus 3. Archives of Virology 152 1541-1546. (doi:10.1007/s00705-007-0975-4)

Drori S, Ofir M, Levavi-Sivan B \& Yaron Z 1994 Spawning induction in common carp (Cyprinus Carpio) using pituitary extract or GnRH superactive analog combined with metoclopramide - analysis of hormone profile, progress of oocyte maturation and dependence on temperature. Aquaculture 119 393-407. (doi:10.1016/00448486(94)90303-4)

Fares FA, Suganuma N, Nishimori K, LaPolt PS, Hsueh AJ \& Boime I 1992 Design of a long-acting follitropin agonist by fusing the C-terminal sequence of the chorionic gonadotropin beta subunit to the follitropin beta subunit. PNAS $\mathbf{8 9} 4304-4308$. (doi:10.1073/ pnas.89.10.4304)

Furuhashi M, Shikone T, Fares FA, Sugahara T, Hsueh AJ \& Boime I 1995 Fusing the carboxy-terminal peptide of the chorionic gonadotropin (CG) $\beta$-subunit to the common $\alpha$-subunit: retention of O-linked glycosylation and enhanced in vivo bioactivity of chimeric human CG. Molecular Endocrinology 9 54-63. (doi:10.1210/mend.9.1.7539107)

Hayakawa Y, Morita T, Kitamura W, Kanda S, Banba A, Nagaya H, Hotta K, Sohn YC, Yoshizaki G \& Kobayashi M 2008 Biological activities of single-chain goldfish follicle-stimulating hormone and luteinizing hormone. Aquaculture 274 408-415. (doi:10.1016/j. aquaculture.2007.12.002)

Hurvitz A, Degani G, Goldberg D, Yom-Din S, Jackson K \& LevaviSivan B 2005 Cloning of FSH, LH, and glycoprotein subunits from the Russian Sturgeon (Acipenser gueldenstaedtii), $\beta$-subunit mRNA expression, gonad development, and steroid levels in immature fish. General and Comparative Endocrinology 140 61-73. (doi:10.1016/j. ygcen.2004.09.019)
Kamei H, Kaneko T \& Aida K 2006 In vivo gonadotropic effects of recombinant Japanese eel follicle-stimulating hormone. Aquaculture 261 771-775. (doi:10.1016/j.aquaculture.2006.08.039)

Kasuto H \& Levavi-Sivan B 2005 Production of biologically active tethered tilapia $\mathrm{LH} \beta \alpha$ by the methylotrophic yeast Pichia pastoris. General and Comparative Endocrinology 140 222-232. (doi:10.1016/j. ygcen.2004.10.016)

Kazeto Y, Kohara M, Miura T, Miura C, Yamaguchi S, Trant JM, Adachi S \& Yamauchi K 2008 Japanese eel follicle-stimulating hormone (Fsh) and luteinizing hormone (Lh): production of biologically active recombinant Fsh and Lh by Drosophila S2 cells and their differential actions on the reproductive biology. Biology of Reproduction 79 938-946. (doi:10.1095/biolreprod.108.070052)

Kime DE \& Bieniarz K 1987 Gonadotropin-induced changes in steroid production by ovaries of the common careCyprinus carnio L. around the time of ovulation. Fish Physiology and Biochemistry 3 49-52. (doi:10.1007/BF02183993)

Ko H, Park W, Kim D-J, Kobayashi M \& Sohn YC 2007 Biological activities of recombinant Manchurian trout FSH and LH: their receptor specificity, steroidogenic and vitellogenic potencies. Journal of Molecular Endocrinology 38 99-111. (doi:10.1677/jme.1.02163)

Kucharczyk D, Kujawa R, Luczynski M, Glogowski J, Babiak I \& Wyszomirska E 1997 Induced spawning in bream, Abramis brama (L), using carp and bream pituitary extract and hCG. Aquaculture Research 28 139-144. (doi:10.1111/j.1365-2109.1997.tb01026.x)

Kulikovsky Z, Marttin FJB \& Yaron Z 1996 A comparison of two spawning-inducing agents for common carp. Israeli Journal of Aquaculture-Bamidgeh 48 108-111.

Levavi-Zermonsky B \& Yaron Z 1986 Changes in gonadotropin and ovarian-steroids associated with oocytes maturation during spawning induction in the carp. General and Comparative Endocrinology 62 89-98. (doi:10.1016/0016-6480(86)90097-3)

Levavi-Sivan B, Golan M, Aizen J \& Elizur A 2008 Fish recombinant gonadotropins. CYBIUM International Journal of Ichthyology 32 17-21.

Levavi-Sivan B, Bogerd J, Mananos EL, Gomez A \& Lareyre JJ 2010 Perspectives on fish gonadotropins and their receptors. General and Comparative Endocrinology 165 412-437. (doi:10.1016/j. ygcen.2009.07.019)

Majumder S, Das S, Moulik SR, Mallick B, Pal P \& Mukherjee D 2015 G-protein coupled estrogen receptor (GPER) inhibits final oocyte maturation in common carp, Cyprinus carpio. General and Comparative Endocrinology 211 28-38. (doi:10.1016/j. ygcen.2014.11.011)

Mazón MJ, Gómez A, Yilmaz O, Carrillo M \& Zanuy S 2014 Administration of follicle-stimulating hormone in vivo triggers testicular recrudescence of juvenile European sea bass (Dicentrarchus labrax). Biology of Reproduction 90 6. (doi:10.1095/ biolreprod.113.110569)

Miller TC, Jaques JT, Szkudlinski MW \& MacKenzie DS 2012 Thyrotropic activity of recombinant human glycoprotein hormone analogs and pituitary mammalian gonadotropins in goldfish (Carassius auratus): insights into the evolution of thyrotropin receptor specificity. General and Comparative Endocrinology 177 70-75. (doi:10.1016/j. ygcen.2012.02.012)

Mylonas CC \& Zohar Y 2001 Use of GnRHa-delivery systems for the control of reproduction in fish. Reviews in Fish Biology and Fisheries 10 463-491. (doi:10.1023/A:1012279814708)

Nagahama Y \& Yamashita M 2008 Regulation of oocyte maturation in fish. Development Growth \& Differentiation 50 195-219. (doi:10.1111/ j.1440-169x.2008.01019.x)

Ohta T, Miyake H, Miura C, Kamei H, Aida K \& Miura T 2007 Folliclestimulating hormone induces spermatogenesis mediated by androgen production in Japanese eel, Anguilla Japonica. Biology of Reproduction 77 970-977. (doi:10.1095/biolreprod.107.062299)

Pang Y \& Thomas P 2009 Involvement of estradiol-17beta and its membrane receptor, G protein coupled receptor 30 (GPR30) 
in regulation of oocyte maturation in zebrafish, Danio rario. General and Comparative Endocrinology 161 58-61. (doi:10.1016/j. ygcen.2008.10.003)

Pang Y \& Thomas P 2010 Role of G protein-coupled estrogen receptor 1, GPER, in inhibition of oocyte maturation by endogenous estrogens in zebrafish. Developmental Biology 342 194-206. (doi:10.1016/j. ydbio.2010.03.027)

Peter RE, Lin H-R \& Van Der Kraak G 1988a Induced spawning of Asian fishes induced ovulation and spawning of cultured freshwater fish in China: advances in application of GnRH analogues and dopamine antagonists. Aquaculture 74 1-10. (doi:10.1016/0044-8486(88)90080-4)

Peter RE, Lin HR \& Van der Kraak G $1988 b$ Induced ovulation and spawning of cultured fresh-water fish in China - advances in application of $\mathrm{GnRH}$ analogs and dopamine antagonists. Aquaculture 74 1-10. (doi:10.1016/0044-8486(88)90080-4)

Roy A, Kucukural A \& Zhang Y 2010 I-TASSER: a unified platform for automated protein structure and function prediction. Nature Protocols 5 725-738. (doi:10.1038/nprot.2010.5)

Sen Gupta C \& Dighe RR 1999 Hyperexpression of biologically active human chorionic gonadotropin using the methylotropic yeast, Pichia pastoris. Journal of Molecular Endocrinology 22 273-283. (doi:10.1677/ jme.0.0220273)

Sen Gupta C \& Dighe RR 2000 Biological activity of single chain chorionic gonadotropin, hCG alphabeta, is decreased upon deletion of five carboxyl terminal amino acids of the alpha subunit without affecting its receptor binding. Journal of Molecular Endocrinology $\mathbf{2 4}$ 157-164. (doi:10.1677/jme.0.0240157)

Sugahara T, Pixley MR, Minami S, Perlas E, Ben-Menahem D, Hsueh AJ \& Boime I 1995 Biosynthesis of a biologically active single peptide chain containing the human common $\alpha$ and chorionic gonadotropin $\beta$ subunits in tandem. PNAS 92 2041-2045. (doi:10.1073/pnas.92.6.2041)

Szkudlinski MW 2004 Recombinant human thyrotropins of the twentyfirst century. Expert Opinion on Pharmacotherapy 5 2435-2440. (doi:10. $1517 / 14656566.5 .12 .2435)$

Szkudlinski MW, Teh NG, Grossmann M, Tropea JE \& Weintraub BD 1996 Engineering human glycoprotein hormone superactive analogues. Nature Biotechnology 14 1257-1263. (doi:10.1038/nbt1096-1257)

Thomas P, Pinter J \& Das S 2001 Upregulation of the maturationinducing steroid membrane receptor in spotted seatrout ovaries by gonadotropin during oocyte maturation and its physiological significance. Biology of Reproduction 64 21-29. (doi:10.1095/ biolreprod64.1.21)

Wallach EE, Tal J, Haddad S, Gordon N \& Timor-Tritsch I 1996 Heterotopic pregnancy after ovulation induction and assisted reproductive technologies: a literature review from 1971 to 1993. Fertility and Sterility 66 1-12. (doi:10.1016/S0015-0282(16)58378-2)

Weenen C, Pena JE, Pollak SV, Klein J, Lobel L, Trousdale RK, Palmer S, Lustbader EG, Ogden RT \& Lustbader JW 2004 Long-acting folliclestimulating hormone analogs containing N-linked glycosylation exhibited increased bioactivity compared with O-linked analogs in female rats. Journal of Clinical Endocrinology and Metabolism 89 5204-5212. (doi:10.1210/jc.2004-0425)

Yaron Z 1995 Endocrine control of gametogenesis and spawning induction in the carp. Aquaculture 129 49-73. (doi:10.1016/00448486(94)00229-H)

Yaron Z \& Levavi-Zermonsky B 1986 Fluctuations in gonadotropin and ovarian steroids during the annual cycle and spawning of the common carp. Fish Physiology and Biochemistry 2 75-86. (doi:10.1007/ BF02264075)

Yaron Z, Bogomolnaya A \& Levavi B 1984 A calibrated carp pituitary extract as a spawning-inducing agent. Special Publication of the European Mariculture Society 8 151-168.

Yaron Z, Gur G, Rosenfeld H \& Levavi-Sivan B 2002 Spawning induction in fish and GnRH regulation of gonadotropins: modes of action. Fisheries Sciences 68 (Supplement 1) 661-666. (doi:10.2331/fishsci.68. sup1_661)

Yaron Z, Bogomolnaya A, Drori S, Biton I, Aizen J, Kulikovsky Z \& LevaviSivan B 2009 Spawning induction in the Carp: past experience and future prospects - a review. Israeli Journal of Aquaculture-Bamidgeh $\mathbf{6 1}$ $5-26$.

Zhou LY, Wang DS, Kobayashi T, Yano A, Paul-Prasanth B, Suzuki A, Sakai F \& Nagahama Y 2007 A novel type of P450c17 lacking the lyase activity is responsible for C21-steroid biosynthesis in the fish ovary and head kidney. Endocrinology 148 4282-4291. (doi:10.1210/ en.2007-0487)

Zohar Y \& Mylonas CC 2001 Endocrine manipulations of spawning in cultured fish: from hormones to genes. Aquaculture 197 99-136. (doi:10.1016/S0044-8486(01)00584-1)

Received in final form 23 November 2016

Accepted 20 December 2016

Accepted Preprint published online 20 December 2016
๑) 2017 Society for Endocrinology Printed in Great Britain 